\title{
Isolation and Optimization of Lipid Production from Drechslera Sp. and Feasibility of using Orange Peel as a Substrate for Growth
}

\author{
Hadeel El-Shall1*, Gadallah Abu-Elreesh¹, Sabha El-Sabbagh², Desouky Abd-El-Haleem ${ }^{1}$ \\ ${ }^{1}$ Environmentla biotechnology department, Genetic engineering and biotechnology research institute, city of \\ Scientific Research and technological applications, 21934 New-Burgelarab City, Alexandria, Egypt \\ 2 Botany and Microbiology department, Faculty of Science, Menoufia University, Egypt \\ Corresponding author: Hadeel El-Shall*
}

\begin{abstract}
This study deals with isolation and optimization of soil origin fungus Drechslera sp. with valued unsaturated fatty acids using orange peel as a substrate. Accordingly, to maximize oil production, various parameters were optimized using 'one variable at a time' strategy followed by employing statistical designs (Plackett-Burman (PBD) \& Response surface methodology (RSM)). The results showed that incubation time, $\mathrm{FeSO}_{4}, \mathrm{pH}$ and yeast extract were the most significant factors influencing lipid accumulation. Therefore, RSM employed to optimize their concentrations. The optimum parameter values were: incubation time $144 \mathrm{~h}, \mathrm{FeSO}_{4} 0.015 \mathrm{~g} / \mathrm{L}, \mathrm{pH} 8.5$ and yeast extract $2 \mathrm{~g} / \mathrm{L}$. Under the optimized conditions, a total biomass of $12 \mathrm{~g} / \mathrm{L}$ with a lipid content of $40.75 \%$ (corresponding to a lipid yield of $4.89 \mathrm{~g} / \mathrm{L}$ ) was achieved. The fatty acid profile revealed production of $41.99 \%$ of unsaturated fatty acids. The feasibility of utilizing orange peel as a sole carbon source proved that it represents a potentially valuable source of single cell oil (SCO) with oil yield of $3.65 \mathrm{~g} / \mathrm{L}$. Its FAME profile revealed an increment of unsaturated fatty acids up to $58.86 \%$ with desirable amounts of polyunsaturated fatty acids (PUFA) $33.31 \%$, this making it as ideal substrate for production of unsaturated fatty acids.
\end{abstract}

Indexing Terms/ Keywords: Single Cell Oil, Plackett-Burman Design, Central Composite Design, Orange Peel, Drechslera Sp., Unsaturated Fatty Acids.

Subject Classification: Biotechnology and Microbiology

Type (Method/Approach): Experimental

Date of Publication: 2018-08-30

DOI: https://doi.org/10.24297/jbt.v7i1.7589

ISSN: 2348-6201

Volume: 07 Issue: 01

Journal: Journal of Advances in Biotechnology

Publisher: CIRWORLD

Website: https://cirworld.com

This work is licensed under a Creative Commons Attribution 4.0 International License. 


\section{Introduction}

The main source of edible oil is plants. However, plants do not produce oil with PUFA longer than C18. In addition, fish act as a source of oil that reaches in length up to that of PUFA. But, fish oil is not preferable source because of its unpleasant odor and the presence of accumulated toxic compounds [1,2]. In recent years, microbial production of oils is gaining importance, which represents a valuable alternative feedstock for oil production and a prospect solution for economy [3]. Oil-bearing microorganisms (Oleaginous) are microbial species including yeasts, filamentous fungi and microalgae that are known for their ability to accumulate intracellular lipids higher than $20 \%$ of their biomass when cultivated in nitrogen-limited and carbon-rich medium $[4,5,6]$. These lipids are termed as single cell oil or microbial oil and considered as a supplementary source of conventional oil from plant and animal origin [7].

The main advantage of microbial oils over conventional oils is that it can be employed as substitutes for expensive lipids which are rare in the plant or animal kingdoms, therefore the basic and applied research are involved in the subject with great interest $[8,9,10,11]$.

Recently, tremendous attention is paid for SCO from oleaginous filamentous fungi. Thus, due to their high productivity, easy scaling-up, less labor required, short life cycles, independence of light energy, and the ability of utilizing a wide range of carbon sources including: wastewater, lignocellulosic materials, agro-industrial wastes. All of that makes fungal lipid competitive in compare to other lipid sources [12].

Moreover, due to their unique biological activities, fungal oil is considered as an important source of unsaturated fatty acids (UFA) including poly and monounsaturated fatty acids such as omega 3 (n-3), omega 6 $(n-6)$, and omega $9(n-9)$ with their nutritional values and clinical applications $[13,14,15]$. These UFAs are represented by alpha-linolenic acid (C18:3n-3, ALA), eicosapentaenoic acid (C20:5n-3; EPA), docosahexaenoic acid (C22:6 n-3, DHA), linoleic (C18: 2 n-6), arachidonic acid (C20:4, n-6 ARA,), $\gamma$-linolenic acid (C18:3n-6, GLA), oleic acid $(C 18: 1 n-9, O A)$ and others $[16,17]$.

Several filamentous fungi are reported as oil producers such as Aspergillus oryzae, Claviceps purpurea, Humicola lanuginose, Mortierella isabellina, Mortierella vinacea and Mucor sp. [18, 19].

The first step for the application of these oleaginous fungi in industrial processes is the optimization of culture conditions for maximizing lipid productivity [20]. This step can be done by experimental statistical designs such as Plackett-burman design and Response Surface methodology which are better approved for optimization compared with the traditional methods of one variable at a time [21] which is highly tedious, not accurate and is often used to screen suitable carbon and nitrogen sources [22]. In contrast, Plackett-burman and RSM methods enhancing the yield of product; reduce incubation time and costs and are preferable from economical point of view [23].

Economic feasibility of SCO production was hampered by the high cost of growth substrates prevented the technology from wider application [24]. Consequently, particular interest in the biotechnological production of microbial oils has focused upon finding zero or negative value waste substrates to achieve sustainable and cost-effective production of oil [25].

Therefore, the objectives of this study were to isolate and select an oleaginous fungal strain able to produce valued unsaturated oils in large amount; by optimizing the environmental, nutritional and cultivation parameters that affect the yield of produced oils. In addition, the possibility of using orange peel as an inexpensive substrate for growth and oil production was examined. 


\section{Materials and Methods}

\subsection{Soil Sampling}

Soil samples from different sites from the garden of City of Scientific research and technological applicationsNew-Burg-Elarab City - Alexandria- Egypt, were collected from a depth of 5-15 cm below the surface, sealed in sterile sampling polyethylene bags and stored at $4{ }^{\circ} \mathrm{C}$ until use.

\subsection{Isolation of fungi}

One gram of each soil sample was individually suspended in $1 \mathrm{~mL}$ of sterile distilled water. Then, serially diluted 10 -fold and plated on potato dextrose agar plates supplemented with $100 \mathrm{mg} / \mathrm{L}$ chloramphenicol (Sigma-Aldrich). Plates were incubated at $30{ }^{\circ} \mathrm{C}$ for 5 days. After incubation period, purification of the obtained fungal colonies were done by single colony culture through transferring the obtained colonies to a new agar plate repeatedly until pure cultures were confirmed, then it was kept on PDA slants at $4^{\circ} \mathrm{C}$.

\subsection{Screening of oleaginous fungi by Nile red staining}

All Isolated fungal strains were screened for lipid accumulation using Nile-red staining assay [26]. Directly, fungal biomass were incubated in dark with $0.5 \mathrm{~mL}$ of $0.1 \mathrm{mM}$ phosphate buffer saline (PBS) $\mathrm{pH} 7.4$ and 0.05 $\mathrm{mL}$ Nile-red solution $(25 \mu \mathrm{g} / \mathrm{mL}$ in acetone). After $30 \mathrm{~min}$, a thin film was prepared on a clean glass slide and retained for air-drying. Examinations were performed using fluorescence microscope (Olympus BX 40).

\subsection{Selection of fungi with the highest lipid yield}

Fungal isolates with the strongest fluorescence were grown separately in triplicate on aliquot of $50 \mathrm{~mL}$ Czapek-Dox's medium (pH 6) in $250 \mathrm{~mL}$ Erlenmeyer flasks for each fungus. After autoclaving and cooling, each flask was inoculated with a disk aseptically removed from the actively growing outer edge of the 5 days aged mycelium on agar PDA plates. Flasks were incubated at $30{ }^{\circ} \mathrm{C}$ for 7 days under static conditions. After incubation, dry biomass, lipid yield and lipid content were determined to select the most oleaginous isolate to further studies.

\subsubsection{Determination of dry biomass}

Harvesting of the mycelia mats of culture broth was done by filtration, then washing 3 times with distilled, finally drying at $60{ }^{\circ} \mathrm{C}$ till constant weight. Dry biomass weight was determined gravimetrically, expressed in $\mathrm{g} / \mathrm{L}$ according to [27] and was crushed into fine powder and preserved in desiccators until use.

\subsubsection{Determination of lipid yield and lipid content}

Lipid yield (the amount of lipid extracted from the biomass per liter of fermentation medium $(\mathrm{g} / \mathrm{L})$ ) determination was done using phospho-vanillin method [28]. To determine the lipid yield, the absorbance at $520 \mathrm{~nm}$ was measured and compared with the standard calibration curve of canola oil [29]. After determining the biomass weight and lipid yield, the lipid content was calculated using the following Equation (1) [30, 31]:

$$
Y=(L / X) * 100 \quad \text { Eq. (1) }
$$

Where, $(\mathrm{Y})$ Lipid content (\%); (L) Lipid yield $(\mathrm{g} / \mathrm{L})$; and $(\mathrm{X})$ Cell dry weight yield $(\mathrm{g} / \mathrm{L})$

\subsection{Identification of the selected isolate}

The isolate with the highest lipid content was identified based on both morphological character and molecular level. Morphological characteristics include macroscopic features of the colonies and examination of the microstructural features were carried out according to [32]. Molecular identification was done on the basis of 
PCR amplification of the 18S rDNA gene. Fungus was allowed to grow for 3 days and genomic DNA was prepared using AMSHAG-DNA Extraction Kit [33]. Then, $0.1 \mu \mathrm{g}$ genomic DNA was used as a template for PCR reaction and the primers used for the amplification of 18S-rDNA encoding genes were those described by [34]. The PCR was run on Thermo PCR machine. Thereafter, $1 \%$ agarose gel containing Ethidium bromide was used to separate the PCR fragment by electrophoresis. Gel was run at $100 \mathrm{~V}$ in $1 \mathrm{X}$ TBE buffer and then visualized using the MultiImage light cabinet of gel documentation (INGENIUS). PCR product was purified using NEPRAS DNA kit [33] and sequenced using 373 API DNA sequencer. The sequence were analyzed using the BLAST program (National Centre for Biotechnology Information) to find out the homology with the existing species. Confirmed sequence was submitted to GenBank.

\subsection{Culture media and optimization of culture conditions for biomass production and lipid accumulation}

Cultivation of the fungus was first performed on the basic Czapek-Dox's medium (in g/L: Sucrose, 30; $\mathrm{NaNO}_{3}$, $2 ; \mathrm{KH}_{2} \mathrm{PO}_{4}, 1 ; \mathrm{MgSO}_{4} .7 \mathrm{H}_{2} \mathrm{O}, 0.5 ; \mathrm{KCL}, 0.5$ and $\left.\mathrm{FeSO}_{4} .7 \mathrm{H}_{2} \mathrm{O}, 0.01\right)$ the $\mathrm{pH}$ was adjusted to 6 using $1.0 \mathrm{M}(\mathrm{HCl}$ or $\mathrm{NaOH}$ ) before autoclaving at $121^{\circ} \mathrm{C}$ for $20 \mathrm{~min}$.

\subsubsection{Optimization of one variable at time (OVAT)}

The influence of different temperatures $\left(10,20,30,40\right.$ and $50{ }^{\circ} \mathrm{C}$ ) and carbon sources $(30 \mathrm{~g} / \mathrm{L}$ ) (sucrose, glucose, lactose, glycerol, starch and carboxy methyl cellulose (CMC)) were examined. The effect of nitrogen sources (sodium nitrate, ammonium chloride, urea, yeast extract, peptone and glutamic acid) were studied and incorporated at $2 \mathrm{~g} / \mathrm{l}$ separately in the basal medium. In addition, different concentrations of $\mathrm{C} / \mathrm{N}$ molar ratios $(30: 1,30: 2,30: 4,30: 6,15: 2,60: 2,60: 4)$, static and shaking conditions (150 rpm) were tested.

Each experiment was prepared in triplicate in $250 \mathrm{~mL}$ Erlenmeyer flasks containing $50 \mathrm{~mL}$ medium. After autoclaving and cooling, each flask was inoculated with a disk from the margin of 5 days aged cells on agar PDA solidified medium in petri dishes and incubated at $30^{\circ} \mathrm{C}$ for 7 days under static conditions, except for the experiment of shaking at $150 \mathrm{rpm}$. Dry biomass, lipid yield and lipid content were determined as described above.

\subsubsection{Statistical experimental design}

\subsubsection{Plackett-Burman design (PBD)}

Eight independent variables (sucrose, yeast extract, $\mathrm{KH}_{2} \mathrm{PO}_{4}, \mathrm{MgSO}_{4} .7 \mathrm{H}_{2} \mathrm{O}, \mathrm{KCl}, \mathrm{FeSO}_{4} .7 \mathrm{H}_{2} \mathrm{O}, \mathrm{PH}$, incubation days) were screened in twelve combinations organized according to the Plackett-Burman design matrix (Table1). Each independent variable was set at two levels: a high $(+1)$ and low $(-1)$ level, the low and high values of each variable are presented in (Table 2). Along with each experiment, biomass, lipid yield and lipid content were determined and lipid content was considered as the response for each trial.

Plackett-Burman experimental design is based on the first order model (Eq.2):

$$
Y=\beta_{0}+\Sigma \beta_{i} X_{i}
$$

Where, $Y$ is the response or dependent variable (lipid content); it will always be the variable we aim to predict, $\beta o$ is the model intercept and $\beta_{i}$ is the linear coefficient, and $X_{i}$ is the level of the independent variable. From the statistical analysis, the main effect was used to elucidate the significance of variables depending on their nature; positive or negative effect on the production process. 
Table (1): Plackette-Burman design matrix for screening of critical factors influencing lipid production by isolate F16

\begin{tabular}{|c|c|c|c|c|c|c|c|c|c|c|}
\hline \multirow{2}{*}{$\begin{array}{l}\text { Variable } \\
\text { s } \\
\text { Trials }\end{array}$} & \multirow[t]{2}{*}{ Sucrose } & \multirow{2}{*}{$\begin{array}{l}\text { Yeast } \\
\text { extrac } \\
t\end{array}$} & \multirow[t]{2}{*}{$\mathrm{KH}_{2} \mathrm{PO}_{4}$} & \multirow{2}{*}{$\begin{array}{l}\mathrm{MgSO}_{4} . \\
7 \mathrm{H}_{2} \mathrm{O}\end{array}$} & \multirow[t]{2}{*}{$\mathrm{KCl}$} & \multirow{2}{*}{$\begin{array}{l}\mathrm{FeSO}_{4} . \\
7 \mathrm{H}_{2} \mathrm{O}\end{array}$} & \multirow[t]{2}{*}{$\mathbf{p H}$} & \multirow{2}{*}{$\begin{array}{l}\text { Incubati } \\
\text { on days }\end{array}$} & \multicolumn{2}{|c|}{ Lipid content\% } \\
\hline & & & & & & & & & $\begin{array}{l}\text { Experimen } \\
\text { tal }\end{array}$ & $\begin{array}{l}\text { Predicte } \\
\text { d }\end{array}$ \\
\hline 1 & 1 & 1 & -1 & 1 & 1 & -1 & 1 & -1 & 7.03 & 9.25 \\
\hline 2 & -1 & -1 & -1 & 1 & 1 & 1 & -1 & 1 & 10.51 & 12.11 \\
\hline 3 & -1 & 1 & -1 & -1 & -1 & 1 & 1 & 1 & 7.09 & 8.64 \\
\hline 4 & -1 & -1 & -1 & -1 & -1 & -1 & -1 & -1 & 4.72 & 3.79 \\
\hline 5 & 1 & 1 & 1 & -1 & 1 & 1 & -1 & 1 & 8.94 & 8.01 \\
\hline 6 & -1 & 1 & 1 & -1 & 1 & -1 & -1 & -1 & 1.38 & 2.31 \\
\hline 7 & 1 & -1 & -1 & -1 & 1 & 1 & 1 & -1 & 5.35 & 3.12 \\
\hline 8 & -1 & 1 & 1 & 1 & -1 & 1 & 1 & -1 & 5.70 & 4.15 \\
\hline 9 & 1 & -1 & 1 & 1 & -1 & 1 & -1 & -1 & 3.44 & 4.99 \\
\hline 10 & 1 & -1 & 1 & -1 & -1 & -1 & 1 & 1 & 30.41 & 32.01 \\
\hline 11 & -1 & -1 & 1 & 1 & 1 & -1 & 1 & 1 & 36.24 & 34.64 \\
\hline 12 & 1 & 1 & -1 & 1 & -1 & -1 & -1 & 1 & 17.84 & 15.61 \\
\hline
\end{tabular}

Table (2): The coded and actual values of experimental variables at different levels

\begin{tabular}{|ccccc|}
\hline & & \multicolumn{3}{c|}{$\begin{array}{c}\text { Coded levels } \\
\text { Experimental values }\end{array}$} \\
\cline { 3 - 5 } & Unite & \multicolumn{3}{|c|}{$\mathbf{+ 1}$} \\
\hline Sucrose & $\mathrm{g} / \mathrm{L}$ & 15 & 30 & 45 \\
Yeast extract & $\mathrm{g} / \mathrm{L}$ & 1 & 2 & 3 \\
$\mathbf{K H}_{\mathbf{2}} \mathbf{P O}_{\mathbf{4}}$ & $\mathrm{g} / \mathrm{L}$ & 0.5 & 1 & 2 \\
$\mathbf{M g S O}_{\mathbf{4} .7 \mathbf{H}_{2} \mathbf{O}}$ & $\mathrm{g} / \mathrm{L}$ & 0.25 & 0.5 & 1 \\
$\mathbf{~ K C l}$ & $\mathrm{g} / \mathrm{L}$ & 0.25 & 0.5 & 1 \\
$\mathbf{F e S O}_{\mathbf{4 . 7}} \mathbf{7} \mathbf{H}_{\mathbf{2}} \mathbf{O}$ & $\mathrm{g} / \mathrm{L}$ & 0.005 & 0.01 & 0.02 \\
$\mathbf{P H}$ & - & 4.5 & 5.5 & 6.5 \\
Incubation days & - & 4 & 7 & 10 \\
\hline
\end{tabular}

\subsubsection{Central composite design (CCD)}

After determining the significant parameters by $\mathrm{PBD}, \mathrm{CCD}$ was employed to optimize their levels. Four parameters were studied independently (yeast extract, $\mathrm{FeSO}_{4} .7 \mathrm{H}_{2} \mathrm{O}, \mathrm{pH}$ and incubation days). Each variable in the design was studied at five different levels $(-2,-1,0,+1,+2)$ and the other variables in the study were maintained at a constant level which gave maximal yield in the PBD experiments. A set of 31 experiments were employed as indicated in (Table 3) and the minimum and maximum ranges of variables were investigated (Table 4). Along with each experiment biomass, lipid yield and lipid content were determined and lipid content was considered as the response for each trial.

For statistical calculation, the relationship between the coded and actual values is described by Eq.3:

$$
\mathrm{X}_{\mathrm{i}}=\mathrm{U}_{\mathrm{i}}-\mathrm{U}_{\mathrm{io}} / \Delta \mathrm{U}_{\mathrm{i}}
$$

Where $X_{i}$ is the coded value of the ith variable, $U_{i}$ is the actual value of the ith variable, $U_{i 0}$ is the actual value of the ith variable at the center point and $\Delta \mathrm{U}_{i}$ is the step change of variable. The response variable (lipid content) suitable to a quadratic equation for the variables was as Eq.4: 
$Y=\beta_{0}+\beta_{1} X_{1}+\beta_{2} X_{2}+\beta_{3} X_{3}+\beta_{4} X_{4}+\beta_{11} X_{1}^{2}+\beta_{22} X_{2}^{2}+\beta_{33} X_{3}^{2}+\beta_{44} X_{4}^{2}+\beta_{12} X_{1} X_{2}+\beta_{13} X_{1} X_{3}+\beta_{14} X_{1} X_{4}+\beta_{23} X_{2} X_{3}+$ $\beta_{24} X_{2} X_{4}+=$ (Eq.4)

Where: $\mathrm{Y}$ is the predicted response; $\mathrm{X} 1, \mathrm{X} 2, \mathrm{X} 3$ and $\mathrm{X} 4$ are input variables which influence the response variable $Y ; \beta 0$, intercept; $\beta 1, \beta 2, \beta 3$ and $\beta 4$ linear coefficients; $\beta 11, \beta 22, \beta 33$ and $\beta 44$, squared or quadratic coefficients $\beta 12, \beta 13, \beta 14, \beta 23$ and $\beta 24$ interaction coefficients

Table (3): Experimental range and levels of the most effective variables used in CCD

\begin{tabular}{|cccccc|}
\hline & \multicolumn{5}{c|}{ Coded levels } \\
Variable & $\mathbf{5}$ & $\mathbf{- 1}$ & $\mathbf{0}$ & $\mathbf{+ 1}$ & $\mathbf{+ 2}$ \\
\cline { 2 - 6 } & $\mathbf{- 2}$ & 0.5 & 1 & 1.5 & 2 \\
Yeast Extract (g/L) & 0.25 & 0.002 & 0.005 & 0.009 & 0.015 \\
FeSO4.7H $\mathbf{H}_{\mathbf{2}} \mathbf{O}$ (g/L) & 0 & 5.5 & 6.5 & 7.5 & 8.5 \\
$\mathbf{P H}$ & 5 & 8 & 10 & 12 & 14 \\
Incubation days (hour) & 6 & 8 &
\end{tabular}

Table (4): Central composite design of the four significant factors with experimental and predicted results of lipid content

\begin{tabular}{|c|c|c|c|c|c|c|}
\hline \multirow[b]{2}{*}{$\begin{array}{l}\text { Run } \\
\text { order }\end{array}$} & \multirow[b]{2}{*}{$\begin{array}{c}\text { Yeast } \\
\text { extract }\end{array}$} & \multirow[b]{2}{*}{$\mathrm{FeSO}_{4 .} .7 \mathrm{H}_{2} \mathrm{O}$} & \multirow[b]{2}{*}{ PH } & \multirow[b]{2}{*}{$\begin{array}{c}\text { Incubation } \\
\text { days }\end{array}$} & \multicolumn{2}{|c|}{ Lipid content $\%$} \\
\hline & & & & & Experimental & Predicted \\
\hline 1 & 0 & -2 & 0 & 0 & 24.05 & 19.42 \\
\hline 2 & 1 & 1 & -1 & -1 & 16.66 & 15.26 \\
\hline 3 & 0 & 0 & 0 & 0 & 24.74 & 25.81 \\
\hline 4 & -2 & 0 & 0 & 0 & 8.33 & 9.23 \\
\hline 5 & -1 & 1 & -1 & 1 & 5.66 & 4.84 \\
\hline 6 & 0 & 0 & 0 & 0 & 25.66 & 25.81 \\
\hline 7 & 0 & 0 & 0 & -2 & 11.31 & 11.31 \\
\hline 8 & -1 & -1 & -1 & -1 & 11.48 & 9.26 \\
\hline 9 & 0 & 0 & 0 & 0 & 26.95 & 25.81 \\
\hline 10 & -1 & -1 & 1 & -1 & 9.00 & 12.06 \\
\hline 11 & 1 & -1 & -1 & -1 & 11.86 & 16.07 \\
\hline 12 & -1 & -1 & 1 & 1 & 3.49 & 3.64 \\
\hline 13 & 1 & 1 & 1 & -1 & 34.38 & 36.21 \\
\hline 14 & 0 & 0 & 0 & 0 & 24.55 & 25.81 \\
\hline 15 & 1 & -1 & 1 & -1 & 35.01 & 34.58 \\
\hline 16 & 2 & 0 & 0 & 0 & 43.26 & 39.04 \\
\hline 17 & 1 & -1 & 1 & 1 & 18.79 & 24.28 \\
\hline 18 & 1 & 1 & 1 & 1 & 23.92 & 24.89 \\
\hline 19 & 1 & -1 & -1 & 1 & 14.35 & 13.94 \\
\hline 20 & 0 & 0 & 0 & 0 & 26.38 & 25.81 \\
\hline 21 & -1 & 1 & -1 & -1 & 7.01 & 6.09 \\
\hline 22 & -1 & -1 & -1 & 1 & 6.29 & 9.03 \\
\hline 23 & 0 & 2 & 0 & 0 & 15.55 & 16.86 \\
\hline 24 & -1 & 1 & 1 & -1 & 12.15 & 11.32 \\
\hline 25 & 0 & 0 & 0 & 0 & 25.50 & 25.81 \\
\hline 26 & 0 & 0 & 0 & 0 & 26.92 & 25.81 \\
\hline 27 & 0 & 0 & 2 & 0 & 22.48 & 18.84 \\
\hline 28 & 1 & 1 & -1 & 1 & 10.61 & 12.12 \\
\hline 29 & 0 & 0 & 0 & 2 & 3.08 & -0.23 \\
\hline 30 & 0 & 0 & -2 & 0 & 2.96 & 3.27 \\
\hline 31 & -1 & 1 & 1 & 1 & 1.54 & 1.89 \\
\hline
\end{tabular}




\subsubsection{Statistical analysis}

All experiments were conducted in triplicates. The experimental results obtained were expressed as means of standard deviation. Experimental matrix and statistical analysis of data of both PBD and CCD, subsequent regression analysis, ANOVA, 3D surface plots \& 2D contour plots and optimizer were performed using Minitab 15 (Minitab Inc., Pennsylvania, USA). The data obtained on lipid yield was subjected for Analysis of Variance (ANOVA) appropriate to the design of the experiments.

\subsection{Lipid production using low cost substrates}

The carbon source in the optimized media was replaced by orange peel, which was sun dried and grounded into fine powder then preserved in desiccators until use. The fungi were inoculated in the production medium and were kept in shaker at $150 \mathrm{rpm}$ at $30^{\circ} \mathrm{C}$ for $144 \mathrm{~h}$.

\subsection{Lipid Extraction}

Extraction of lipids was performed according to the method of [35]. The dry biomass was grounded with mixture of chloroform: methanol (2:1) and agitated for $20 \mathrm{~min}$ at $200 \mathrm{rpm}$ at room temperature and centrifuged at $6000 \mathrm{rpm}$ for $10 \mathrm{~min}$ to recover solvent phase. The same process was repeated two times. The solvent was evaporated and samples were dried under vacuum, and then the amount of oil is recorded using gravimetric method.

\subsection{Trans-esterification of extracted lipid}

The fungal lipid obtained was mixed vigorously with $20 \mathrm{~mL}$ of methanol and $2 \mathrm{~mL}$ of concentrated sulphuric acid for 2 hours at $70^{\circ} \mathrm{C}$. After the completion of the reaction, the mixture was allowed to cool at room temperature and then transferred to separating funnel for obtaining two layers containing upper methyl ester layer and lower glycerol layer. The methyl ester was collected and analyzed using GC-MS. It was performed with Agilent 6890N Gas Chromatograph connected to Agilent 5973 Mass Spectrometer at 70 eV (m/z 50-550; source at $230{ }^{\circ} \mathrm{C}$ and quadruple at $150^{\circ} \mathrm{C}$ ) in the EI mode with an HP-5ms capillary column $\left(30 \mathrm{~m}^{\prime} 0.25 \mathrm{~mm}\right.$ i.d., $0.25 \mathrm{~mm}$ film thickness; J \& W Scientific, USA). The carrier gas, helium, was maintained at a flow rate of 1.0 $\mathrm{mL} / \mathrm{min}$. The inlet temperature was maintained at $300{ }^{\circ} \mathrm{C}$ and the oven was programmed for $2 \mathrm{~min}$ at $150{ }^{\circ} \mathrm{C}$, then increased to $300^{\circ} \mathrm{C}$ at $4{ }^{\circ} \mathrm{C} / \mathrm{min}$, and maintained for $20 \mathrm{~min}$ at $300^{\circ} \mathrm{C}$. The injection volume was $1 \mathrm{~mL}$, with a split ratio of 50:1. Structural assignments were based on interpretation of mass spectrometric fragmentation and confirmed by comparison of retention times, fragmentation pattern of authentic compounds and the spectral data obtained from the Wiley and NIST libraries.

\section{3- Results and discussion}

\subsection{Screening for lipids inside fungal isolates}

About 22 fungal isolates designated as F1 to F22 were isolated from soil samples obtained from the garden of the City of Scientific research and Technological Applications. They were screened for lipid accumulation by Nile red staining assay. This assay was employed simply to recognize oleaginous lipid species from nonoleaginous as; Nile red reacts only with storage lipid droplets and gives positive red fluorescence signals, which can be detected by fluorescence spectroscopy. Out of screening assay, five isolates were exhibited with the strongest red fluorescence under fluorescent microscope as indicated in table (5), so these isolates were selected for further study. 
Table (5): Screening for lipids inside fungal isolates by Nile red staining assay

\begin{tabular}{|ll|}
\hline Isolate code & Intensity of emitted red fluorescence \\
\hline F1 & + \\
F2 & +++ \\
F3 & ++ \\
F4 & ++ \\
F5 & +++ \\
F6 & ++ \\
F7 & ++ \\
F8 & + \\
F9 & ++ \\
F10 & + \\
F11 & + \\
F12 & +++ \\
F13 & ++ \\
F14 & + \\
F15 & ++ \\
F16 & +++ \\
F17 & + \\
F18 & ++ \\
F19 & +++ \\
F20 & + \\
F21 & + \\
F22 & ++ \\
\hline
\end{tabular}

* based on the fluorescence signals, $(+++)$ is designed to express high lipid accumulation, $(++)$ for moderate lipid accumulation and (+) for low lipid accumulation. As an example, for the results, the difference between high and moderate lipid accumulation was indicated in Figure (1).
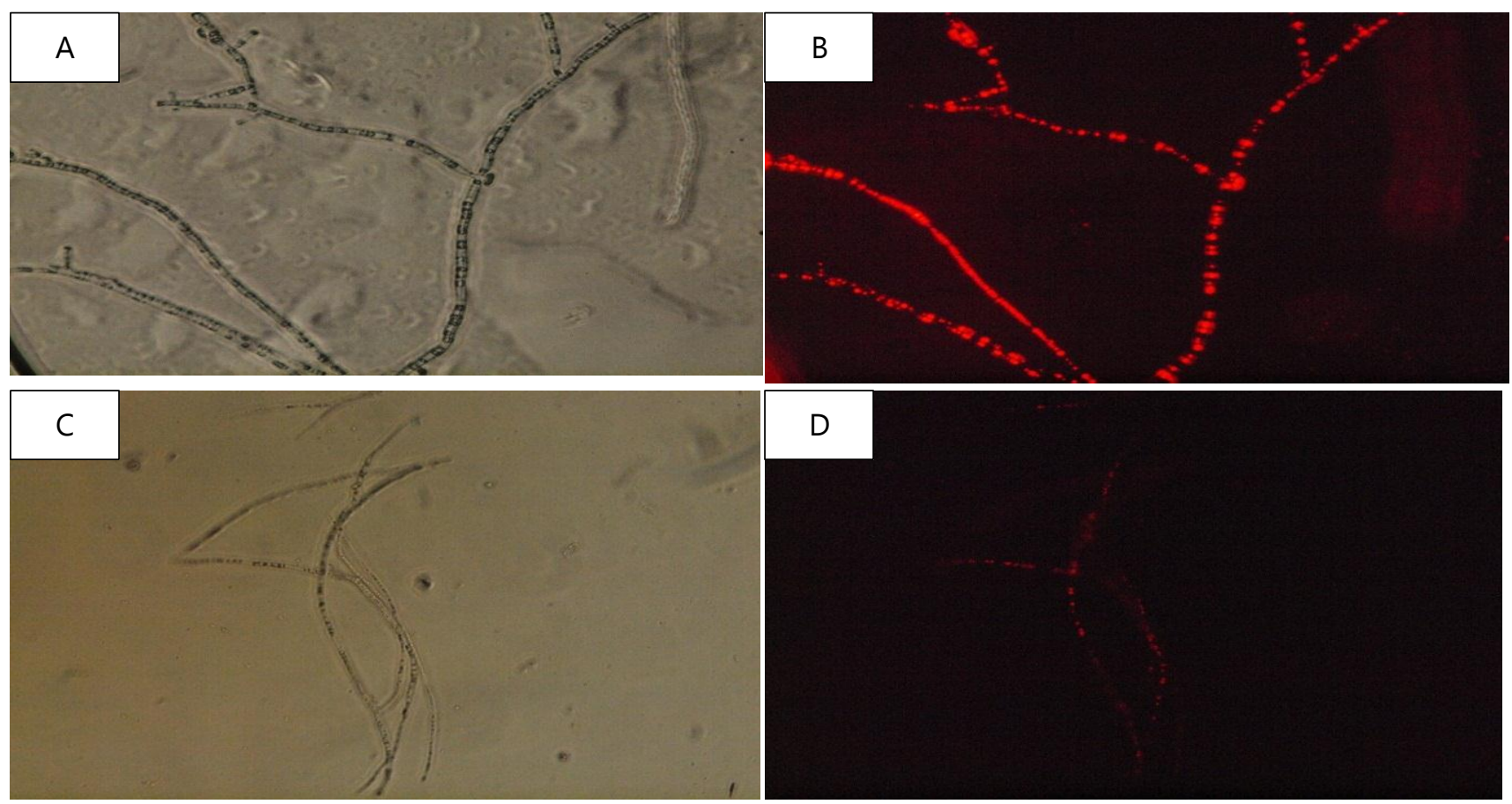

Figure (1): ( $A$ and $C$ ) Ordinary Light image for mycelia of isolates $F 2$ and F3, (B and D) Fluorescence Light image for mycelia of isolate F2 and F3, respectively. 


\subsection{Selection of the isolate with the highest lipid content}

Out of the five isolates, selection of the best one was based on their lipid content. As presented in Table 6, isolate F16 that exhibited the highest lipid content (21.09\%) was selected for further studies.

Table (6): Biomass, lipid yield and lipid content of the five selected isolates which gave the strongest red fluorescence signials.

\begin{tabular}{|ccccc|}
\hline No. & $\begin{array}{c}\text { Isolate } \\
\text { code }\end{array}$ & $\begin{array}{c}\text { Biomass } \\
\mathbf{( g / L )}\end{array}$ & $\begin{array}{c}\text { Lipid yield } \\
\mathbf{( g / L )}\end{array}$ & Lipid content (\%) \\
\hline $\mathbf{1}$ & F 2 & 11 & 2.05 & 18.6 \\
$\mathbf{2}$ & F 5 & 10 & 2.08 & 20.8 \\
$\mathbf{3}$ & F 12 & 10.1 & 2.1 & 20.7 \\
$\mathbf{4}$ & F 16 & 11 & 2.32 & 21.09 \\
$\mathbf{5}$ & F 19 & 10.1 & 2.1 & 20.6 \\
\hline
\end{tabular}

\subsection{Identification of oleaginous isolate $\mathrm{F} 16$}

Based on the sequence analysis of $18 \mathrm{~S}$ rDNA gene of isolate F16 in compare to relative sequences present in the GenBank, isolate F16 was mostly closely related to Alternaria sp. However, microscopic features of conidia showed that the fungus is belonging strongly to the genus of Drechslera sp. According to [32], the conidia are cylindrical (not curved) straight and are transversely septate (Figure 2), while the conidia of Alternaria sp. is characterized by longitudinal and transverse septate. So, based on this, the oil producing isolate F16 was identified as Drechslera sp. Based on that, the 18S rDNA sequence of isolate F16 was submitted to the GenBank and gain accession number MH348917. Isolate F16 is named and designed as Drechslera sp. strain GH3.

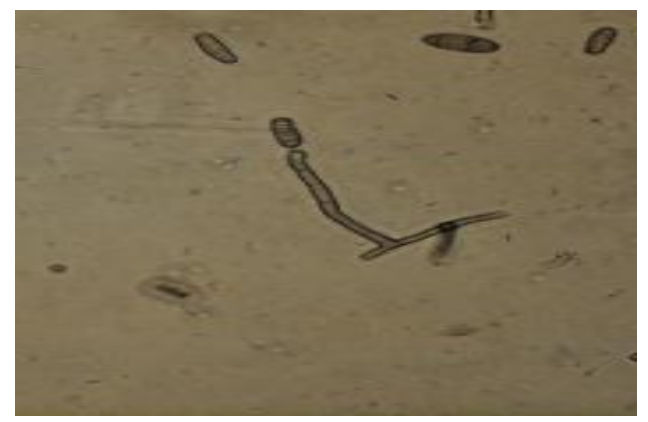

Figure (2) : Microscopic features of isolate F16.

\subsection{Optimization of one variable at time (OVAT)}

It was previously reported that nutritional, environmental and cultivation parameters have pronounced effect on lipid production [36, 37]. Consequently, for achieving maximum lipid productivity by Drechslera sp., biomass and lipid yield of the fungus were investigated at different parameters. 


\subsubsection{Comparison between shaking and static culture incubations}

Results depicted in Table (7) implied that static and shaking incubation conditions can be considered satisfactory for lipid production by the fungus, where, the difference between results of both cultivation modes was considered neglected. The obtained biomass and lipid yield were $11.4 \mathrm{~g} / \mathrm{L}$ and $2.44 \mathrm{~g} / \mathrm{L}$, respectively under static condition. Whereas, under shaking condition were $11.04 \mathrm{~g} / \mathrm{L}$ and $2.34 \mathrm{~g} / \mathrm{L}$, respectively. Similarly, [38] reported that static condition was higher in lipid accumulation than shaking condition. This may be due to the aeration level which has a great effect on fungal growth and its ability to accumulate lipids [39]. On the contrary, [40] reported that biomass and lipid production by Mucor rouxii and Mucor sp. in static cultures was less when compared to the well-aerated cultures under shaking conditions.

\subsubsection{Effect of temperatures}

The critical influence of temperature on lipid accumulation by oleaginous microorganisms has been demonstrated by [30]. Thus, the optimum temperature for maximum lipid yield by Drechslera sp. was studied at temperature range of $\left(10\right.$ to $40^{\circ} \mathrm{C}$ ) (Table 7). Results informed that the lowest lipid content was obtained at $40{ }^{\circ} \mathrm{C}(1.65 \%)$, while the highest at $30{ }^{\circ} \mathrm{C}(21.59 \%)$. Additionally, decrease in biomass and lipid content was noticed with decreasing or increasing incubation temperature compared with $30{ }^{\circ} \mathrm{C}$ as reported by [41]. Therefore; $30{ }^{\circ} \mathrm{C}$ temperature was selected as the optimum temperature for further studies. These results are in accordance with previous reports by $[42,43]$.

\subsubsection{Effect of carbon sources}

Table (7) pointing out the ability of Drechslera sp. to assimilate different carbon sources (monosaccharaides, disaccharides, polysaccharides, and glycerol), with variable amounts of biomass in the range of (4.74: 11.13 $\mathrm{g} / \mathrm{L}$ ) and lipid yield (0.06: $2.45 \mathrm{~g} / \mathrm{L}$ ). Sucrose seemed to be the most favorable carbon source, with the maximum lipid content $(22.04 \%)$, followed by glucose $(21.99 \%)$. While, the lowest lipid content (1.32 \%) was obtained with CMC. In agreement with these results, [44] showed that when Mucor circinelloides was cultivated on sucrose, it produced biomass of $9.83 \mathrm{~g} / \mathrm{L}$ and lipid yield of $2.03 \mathrm{~g} / \mathrm{L}$ with the mycodiesel content of $20.69 \%$.

\subsubsection{Effect of nitrogen sources}

Among the nitrogen sources tested, yeast extract was the best source for biomass and lipid production followed by sodium nitrate then peptone as presented in Table (7). Likewise, [45] proved that the highest lipid content for Rhodosporidium toruloides was achieved using $2.5 \mathrm{~g} / \mathrm{L}$ of yeast extract. The possible explanation for this result is that yeast extract contains amino acids, peptides, vitamins and many micronutrients, which have a remarkable role in stimulating cell growth and proliferation [46, 47].

\subsubsection{Effect of carbon/nitrogen ratio}

As displayed in Table (7), C/N ratio (30:2) was found to be the best for maximum lipid yield and lipid content, while maximum biomass was obtained at 30:6. It was noticeable that as the concentration of yeast extract increased to 4 and $6 \mathrm{~g} / \mathrm{L}$ the lipid yield decline and the cell biomass increase. Referring to [48] higher concentration of nitrogen source is beneficial to cell growth but not to lipid accumulation. Concerning this, [49] reported that to promote energy storage in microbial cells (lipid accumulation), a starvation step is required. To achieve this, the starting concentration of nitrogen in the culture medium should be limited relative to the carbon source (high $\mathrm{C} / \mathrm{N}$ ratio) [50]. This probably due to inhibition of isocitrate dehydrogenase during nitrogen limitation, so citrate is accumulated in the cytoplasm and then is transported into the mitochondria. In the mitochondrial membrane, efflux system is existed between citrate and malate, so citrate enters the cytosol where it is cleaved to acetyl-CoA by ATP citrate lyase (ACL) [49]. this may be attributed to the inhibitory effect of high substrate concentration on growth and lipid accumulation due to high osmotic stress [47] as observed in T. fermentans CICC 1368 [51]. Anyway, the C/N molar ratio 30:2 was used in the subsequent experiments. 
Table (7): The effect of some nutritional and incubational parameters on cell growth and lipid accumulation of Drechslera sp.

\begin{tabular}{|c|c|c|c|}
\hline Parameter & $\begin{array}{c}\text { Biomass } \\
(g / L)\end{array}$ & $\begin{array}{l}\text { Lipid yield } \\
\qquad(g / L)\end{array}$ & $\begin{array}{l}\text { Lipid content } \\
\qquad(\%, w / w)\end{array}$ \\
\hline \multicolumn{4}{|l|}{ Static or shaking } \\
\hline Static & 11.4 & 2.44 & 21.4 \\
\hline Shaking & 11.04 & 2.34 & 21.19 \\
\hline \multicolumn{4}{|l|}{ Temperature ${ }^{\circ} \mathrm{C}$} \\
\hline 10 & 1.75 & 0.05 & 2.99 \\
\hline 20 & 7.73 & 0.79 & 10.34 \\
\hline 30 & 11.33 & 2.44 & 21.59 \\
\hline 40 & 2.73 & 0.04 & 1.65 \\
\hline \multicolumn{4}{|l|}{ Carbon source } \\
\hline Sucrose & 11.13 & 2.45 & 22.04 \\
\hline Glucose & 10.71 & 2.35 & 21.99 \\
\hline Lactose & 7.49 & 0.93 & 12.67 \\
\hline Glycerol & 6.70 & 0.74 & 11.10 \\
\hline Starch & 8.03 & 0.79 & 9.92 \\
\hline CMC & 4.74 & 0.06 & 1.32 \\
\hline \multicolumn{4}{|l|}{ Nitrogen source } \\
\hline Sodium nitrate & 11.1 & 2.40 & $21.64^{`}$ \\
\hline Peptone & 6.14 & 1.26 & 20.57 \\
\hline Ammonium chloride & 3.67 & 0.52 & 14.16 \\
\hline Yeast extract & 11.72 & 2.78 & 23.71 \\
\hline Urea & 3.18 & 0.44 & 13.85 \\
\hline Glutamic acid & 2.62 & 0.21 & 8.18 \\
\hline \multicolumn{4}{|l|}{$\mathrm{C} / \mathrm{N}$ ratio } \\
\hline $15: 2$ & 7.09 & 0.63 & 8.94 \\
\hline $30: 1$ & 7.91 & 1.00 & 12.75 \\
\hline $30: 2$ & 11.53 & 2.71 & 23.57 \\
\hline $30: 4$ & 13.04 & 1.94 & 14.87 \\
\hline $30: 6$ & 14.04 & 1.68 & 12.01 \\
\hline $60: 2$ & 13.1 & 1.26 & 9.68 \\
\hline
\end{tabular}




\section{Screening of significant variables using Plackett-Burman design}

Plackett-Burman statistical design of twelve runs was employed to analyze the influence of eight variables on the response value (lipid content) for Drechslera sp..

Results in Table (1) revealed that there is a variation in lipid content ranging from 1.38 to $36.24 \%$ which represents lipid yield $(0.079 \pm 0.001 \mathrm{~g} / \mathrm{L})$ and $(2.37 \pm 0.005 \mathrm{~g} / \mathrm{L})$, respectively. This variation of lipid content for Drechslera sp. throughout the 20 experimental trials reflected that these factors under experiments showed a strong influence on lipid accumulation by the fungus.

Statistical significance of independent variables coefficients are checked by P-values (probability of error value) and student T-test [52]. Generally, the larger the magnitude of "T-value" with a low probability P-value (less than 0.05 ) indicates high significance of corresponding coefficient $[53,54,55]$.

Accordingly, yeast extract, $\mathrm{pH}$, incubation days and $\mathrm{FeSO}_{4} .7 \mathrm{H}_{2} \mathrm{O}$ were the significant components influencing lipid accumulation for Drechslera sp.. Additionally, the sign of t-value and corresponding coefficient are considered as a valuable tool to determine their positive or negative effects on response [56]. The positive sign coefficient causes increasing in response (lipid content) at higher levels of it, while increasing in response is associated with lower levels of negative sign coefficient as highlighted from Table (8).

Consequently, the coefficient's sign of each independent variable indicated that yeast extract and $\mathrm{FeSO}_{4} .7 \mathrm{H}_{2} \mathrm{O}$ had a negative effect and the other factors displayed a positive effect on lipid content of Drechslera sp. (Table 8).

On application of the standard analysis of variance (ANOVA), it was found that the first order model for lipid content was fitted to the results obtained from the 20 experiments as the following equation (Eq.5)

Lipid content $\%=11.559+0.613$ Sucrose -3.558 Yeast extract $+2.798 \mathrm{KH}_{2} \mathrm{PO}_{4}+1.906 \mathrm{MgSO}_{4} .7 \mathrm{H}_{2} \mathrm{O}+0.021 \mathrm{KCl}$ $-4.716 \mathrm{FeSO}_{4} .7 \mathrm{H}_{2} \mathrm{O}+3.75 \mathrm{pH}+6.951$ incubation days (Eq.5)

Table (8): Statistical analysis of the Plackett-Burman experiment design

\begin{tabular}{|c|c|c|c|c|c|}
\hline Term & Effect & Coef. & SE Coef. & $\mathbf{T}$ & $\mathbf{P}$ \\
\hline \multicolumn{2}{|l|}{ Constant } & 11.559 & 0.9483 & 12.19 & 0.001 \\
\hline Sucrose & 1.225 & 0.613 & 0.9483 & 0.65 & 0.564 \\
\hline Yeast extract & -7.115 & -3.558 & 0.9483 & -3.75 & 0.033 \\
\hline $\mathrm{KH}_{2} \mathrm{PO}_{4}$ & 5.597 & 2.798 & 0.9483 & 2.95 & 0.06 \\
\hline $\mathrm{MgSO}_{4} .7 \mathrm{H}_{2} \mathrm{O}$ & 3.813 & 1.906 & 0.9483 & 2.01 & 0.138 \\
\hline $\mathrm{KCl}$ & 0.041 & 0.021 & 0.9483 & 0.02 & 0.984 \\
\hline 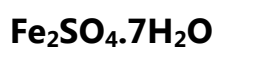 & -9.431 & -4.716 & 0.9483 & -4.97 & 0.016 \\
\hline pH & 7.5 & 3.75 & 0.9483 & 3.95 & 0.029 \\
\hline Incubation days & 13.902 & 6.951 & 0.9483 & 7.33 & 0.005 \\
\hline \multicolumn{2}{|c|}{$S=3.28518 \quad R-S q=97.95 \%$} & \multicolumn{3}{|c|}{$R-S q(\operatorname{adj})=91.51 \%$} & \\
\hline
\end{tabular}

In addition, The Pareto chart Figure (3) identifies the order of significance of variables. For a $95 \%$ confidence level and three degree of freedom, the $t$ value equals 3.18 and shown in the plot as a vertical red line. This indicates the minimum statically effect for $95 \%$ confidence level. Clearly, incubation time was found as the most significant parameter affecting lipid content and the rest factors were not significant as their values not exceed the t-value (red line). 


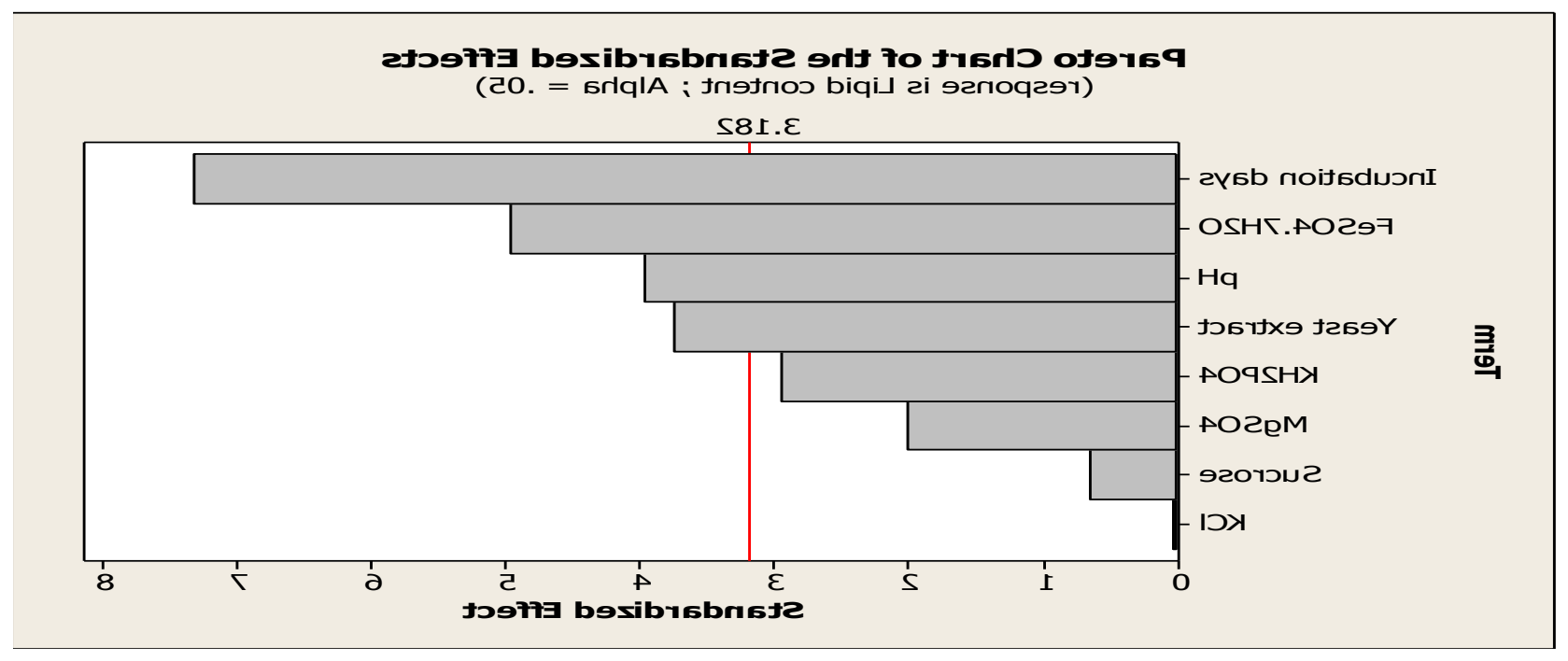

Figure (3): Pareto chart indicating the significance of the variables affecting lipid production

From the standard analysis of variance (ANOVA) the adequacy and significance of the model were proved from the small P-value (0.024). Moreover, the model F-value, which predicts the quality of the entire model considering all design factors at the time as reported by [57] is 15.17, which demonstrated that the model was significant Table (9).

Table (9): Analysis of variance of placket-Burman design

\begin{tabular}{|llllll|}
\hline Source & DF & SS & MS & F & P \\
\hline Regression & 8 & 1309.37 & 163.67 & 15.17 & 0.024 \\
Residual Error & 3 & 32.38 & 10.79 & & \\
Total & 11 & 1341.75 & & & \\
\hline
\end{tabular}

The efficiency of the model can be checked from values of determination coefficient R-Sq and adjusted R-Sq. As R-Sq values determine to how much the variability in the observed response values can be described by the experimental factors and their interactions [45].

As represented in Table (8) the values of $\mathrm{R}-\mathrm{Sq}$ is 0.9795 , denoting that the total variation of $97 \%$ for lipid content is attributed to the independent variables and only about $3 \%$ of the total variation cannot be explained by the model. The closer the value of R-Sq to 1 , the better predicted response and the better correlation between the experimental and predicted values $[58,59]$.

The adjusted R-Sq was $91.15 \%$, which was in good agreement with the R-Sq and this indicates that the proposed model was reasonable. Overall, the above mentioned findings proved the strongest of the model [60].

\subsection{Optimization of significant variables using CCD}

The optimum levels of the determined significant factors were predicted using CCD. Results of 31 RSM experiments of the four significant factors affecting lipid content of Drechslera sp. (yeast extract (X1),

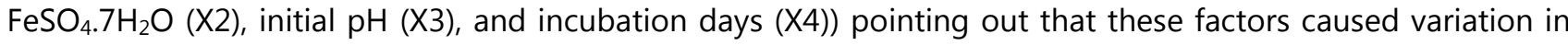
lipid content ranging from $1.54 \%$ (the lowest value) at trial number 31 to $43.26 \%$ (the highest value) at trial 
16 (Table 4). This variation, clarified that these factors act as limiting factors, and little variation in their values will alter the production rate [61].

According to T-value and P-value illustrated in Table (10) the linear effects of (X1, X3 and X4), quadratic effects of $(X 2, X 3$ and $X 4)$ and interaction effect between $\left(X 1^{*} X 3 \& X 3^{*} X 4\right)$ are significant.

Table (10): Estimated regression coefficients for second order polynomial model for Drechslera sp.

\begin{tabular}{|c|c|c|c|c|}
\hline Term & Coef & SE Coef & $\mathbf{T}$ & $\mathbf{P}$ \\
\hline Constant & 25.8186 & 1.1673 & 22.117 & 0 \\
\hline X1 & 7.4509 & 0.6304 & 11.819 & 0 \\
\hline $\mathbf{X} 2$ & -0.6393 & 0.6304 & -1.014 & 0.326 \\
\hline X3 & 3.892 & 0.6304 & 6.174 & 0 \\
\hline X4 & -2.8889 & 0.6304 & -4.582 & 0 \\
\hline$X 1 * X 1$ & -0.42 & 0.5776 & -0.727 & 0.478 \\
\hline$X 2 * \times 2$ & -1.9183 & 0.5776 & -3.321 & 0.004 \\
\hline$X 3 * X 3$ & -3.6893 & 0.5776 & -6.388 & 0 \\
\hline$X 4 * \times 4$ & -5.0695 & 0.5776 & -8.777 & 0 \\
\hline$X 1 * X 2$ & 0.5917 & 0.7721 & 0.766 & 0.455 \\
\hline X1*X3 & 3.9305 & 0.7721 & 5.091 & 0 \\
\hline$X 1 * X 4$ & -0.4736 & 0.7721 & -0.613 & 0.548 \\
\hline$\times 2 * \times 3$ & 0.6087 & 0.7721 & 0.788 & 0.442 \\
\hline$x 2 * \times 4$ & -0.2532 & 0.7721 & -0.328 & 0.747 \\
\hline$X 3 * \times 4$ & -2.044 & 0.7721 & -2.647 & 0.018 \\
\hline
\end{tabular}

From the analysis of variance (ANOVA) of the model regression, it was apparent that the model was significant; indicated by F-value 24.71 and the lower P-value (0.000) (Table 11).

Table (11): Analysis of variance (ANOVA) for optimization of lipid production by Drechslera sp. using central composite design

\begin{tabular}{|cccc|cl|}
\hline & Df & SS & MS & F-test & P-value \\
\hline Regression & 14 & 3299.74 & 235.696 & 24.71 & 0.000 \\
Residual & 16 & 152.62 & 9.539 & & \\
Total & 30 & 3452.36 & & & \\
\hline
\end{tabular}

A second-order polynomial equation was obtained by applying multiple regression analysis to experimental data, to defines the predicted response $(Y)$ in terms of the independent variables $(X 1, X 2, X 3$, and $X 4)$ was obtained (Eq. 6)

$Y=25.8186+7.4509 X 1-0.6393 X 2+3.892 X 3-2.8889 X 4+0.5917 X 1 * X 2+3.9305 X 1 * X 3-0.4736 X 1 * X 4+$ $0.6087 X 2 * X 3-0.2532 X 2 * X 4-2.044 X 3 * X 4-0.42 X 12-1.9183 \times 22-3.6893$ X32- 5.0695 X42 $\quad$ (Eq. 6)

Where $\mathrm{Y}$ is the response (lipid content); $\mathrm{X} 1, \mathrm{X} 2, \mathrm{X} 3$, and $\mathrm{X} 4$ are the coded values of yeast extract, $\mathrm{FeSO}_{4} .7 \mathrm{H}_{2} \mathrm{O}$, $\mathrm{pH}$ and incubation days, respectively.

The R-Sq of the model was 0.956 , pointing out the accuracy of the model as it indicated that $95.6 \%$ of variability in the response could be explained by the model and only $4.4 \%$ could be occurred due to noise. Furthermore, this ensures a satisfactory fitting of the quadratic model to the experimental data. In addition, the value of the adjusted R-Sq is also very high (91.7\%), which is very close to the R-Sq value and this representing a good agreement between the experimental and predicted values [62].

Remarkably, the interactions between the significant factors can be elucidated through 3D response surface plots, these curves were the graphical representations of the regression model and act as a function of two factors at a time keeping the other factors fixed [63]. 
As illustrated in Figure (4.1) a synergistic interaction was exhibited between yeast extract concentration and $\mathrm{FeSO}_{4} .7 \mathrm{H}_{2} \mathrm{O}$ concentration, implying high lipid content associated with elevating concentration of both examined variable.

By maintaining $\mathrm{FeSO}_{4} .7 \mathrm{H}_{2} \mathrm{O}$ and incubation days at their zero level, more than $40 \%$ of lipid content was predicted with $2 \mathrm{gm}$ yeast extract and (8.5) $\mathrm{pH}$ as depicted from Figure (4.2).

However, more than $30 \%$ of lipid content of Drechslera sp. was attained with $2 \mathrm{gm}$ of yeast extract and 6 days incubation time. Upon incubation Drechslera sp. for 14 days, the lipid content decreased, indicating antagonistic interaction (Figure 4.3).

Obviously from Figure (4.4), the increase in the values of $\mathrm{FeSO}_{4} .7 \mathrm{H}_{2} \mathrm{O}$ concentration and $\mathrm{pH}$ to a certain limit led to maximize the lipid content. While, further increase led to gradual decrease in the lipid content.

As shown in Figure (4.5), the antagonistic interaction between $\mathrm{FeSO}_{4} .7 \mathrm{H}_{2} \mathrm{O}$ concentration and incubation time. The plot illustrated that the high level of incubation time supported a high lipid yield. On the other hand high levels of $\mathrm{FeSO}_{4} .7 \mathrm{H}_{2} \mathrm{O}$ inhibited lipid production.

As noticed from Figure (4.6), the higher lipid content was obtained at higher level of $\mathrm{pH}$, while maintaining incubation days at intermediate level. Up on increasing incubation of Drechslera sp. in higher $\mathrm{pH}$ level, the lipid content of Drechslera sp. decreased. 
Finally, Response optimizer tool was used to identify the exact optimum values of each tested variable that leads to achieving response goals. The results of the response optimizer at optimum levels of significant factors for maximum goals are shown in Figure (5). The optimum values for obtaining $40 \%$ lipid content of Drechslera sp. were $(2 \mathrm{~g} / \mathrm{L})$ yeast extract, $(0.015 \mathrm{~g} / \mathrm{L}) \mathrm{FeSO}_{4} .7 \mathrm{H}_{2} \mathrm{O}$ and $(8.5) \mathrm{pH}$ for $144 \mathrm{~h}$ incubation time.

(1)

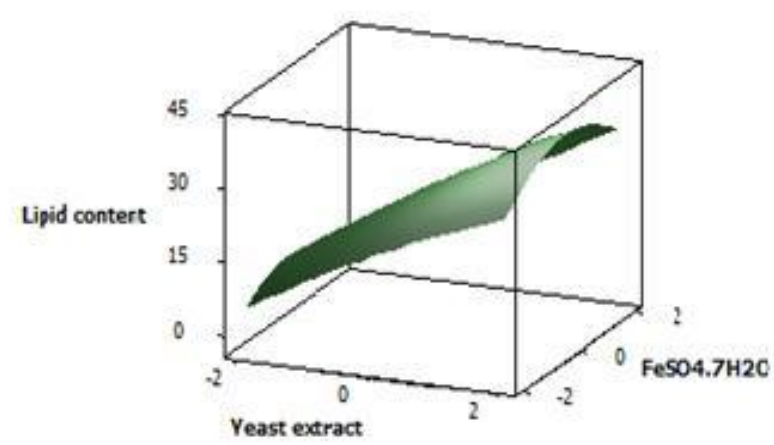

(2)

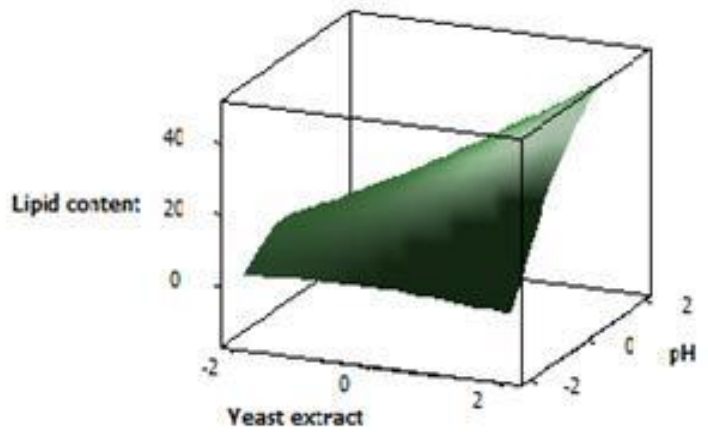

(3)

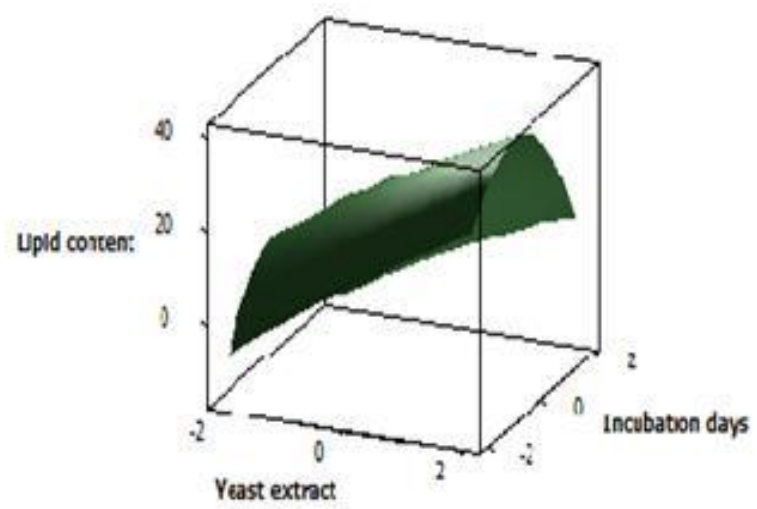

(4)

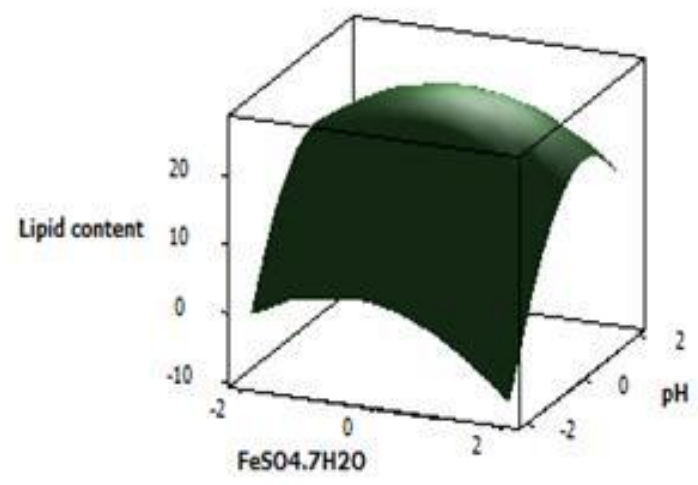

(5)

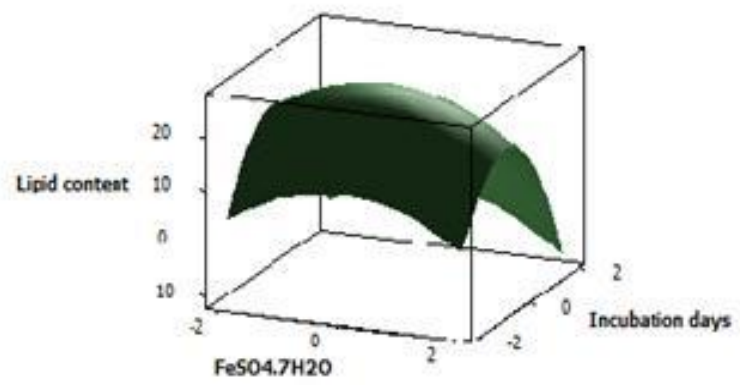

(6)

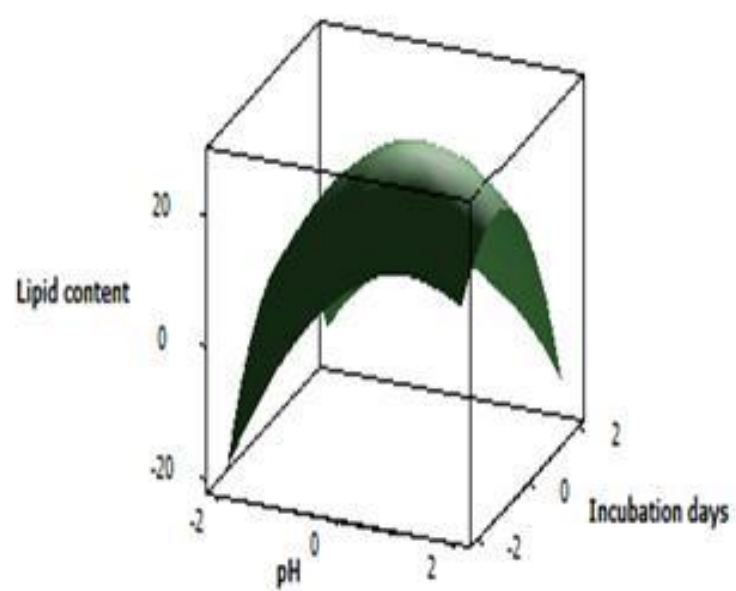

Figure (4): Three-dimensional response surface plots (1-6) showing the interactive effects of independent variables 


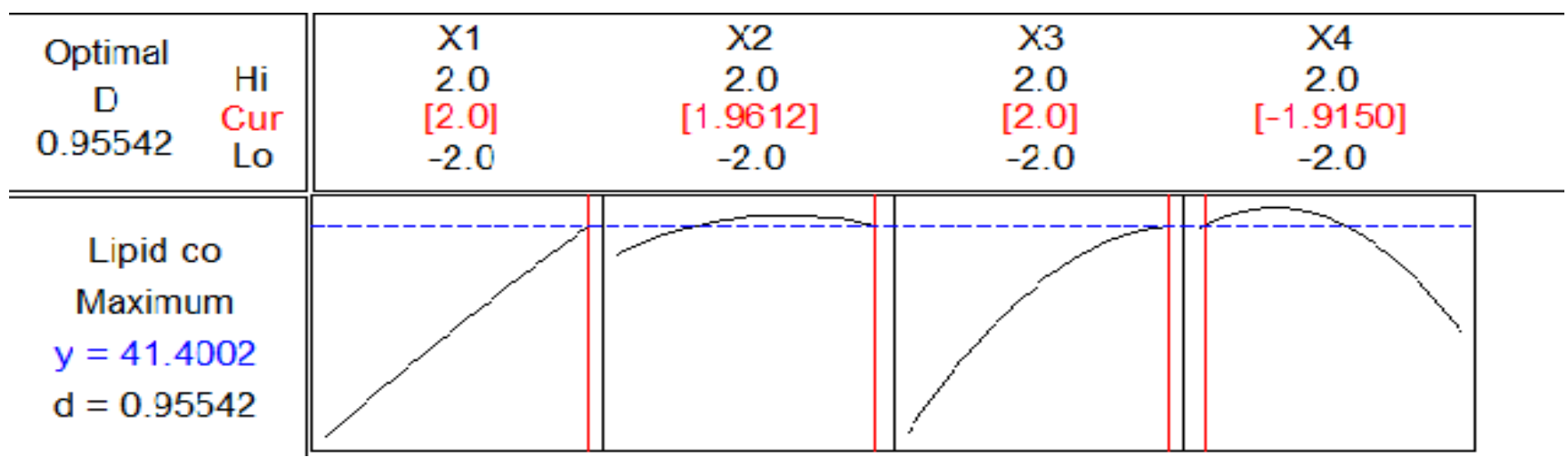

Figure (5): Response optimizer for optimum concentrations of significant variables affecting lipid content of Drechslera sp..

Generally, incubation day's is a significant parameter for lipid production. It was obvious that lipid content reaches its highest value at stationary phase of microbial growth, thus, to prevent lipid degradation it is recommended that cells should be harvested at this stage [64].

The fact that mineral salts including $\mathrm{MnSO}_{4}, \mathrm{ZnSO}_{4}, \mathrm{MgSO}_{4}, \mathrm{COCl}_{2}, \mathrm{CuSO}_{4}$ and $\mathrm{FeSO}_{4}$ at appropriate concentrations have a profound effect on cell growth and lipid accumulation [65, 66], confirmed the significance of $\mathrm{FeSO}_{4} .7 \mathrm{H}_{2} \mathrm{O}$ for lipid production in our study. This may be related to their role as cofactors required by key enzymes implicated in lipid biosynthesis pathway [67]. As reported by [68], who mentioned that acetyl-CoA carboxylase requires bivalent metal ions as the cofactor.

The $\mathrm{pH}$ of the medium affects the availability of metal ions, cell permeability and enzymatic activity. Subsequently, $\mathrm{pH}$ was reported as an important environmental factor affecting cell growth and products formation [69]. It was informed that at pH 6-8.5 Fatty Acid Synthases can create a bond with NADPH well [70].

So far, nitrogen source was demonstrated as the key nutritional factor in the medium controlling lipid accumulation process [71]. During the growth phase nitrogen was utilized for the synthesis of proteins and nucleic acids, under nitrogen exhausted conditions cell growth stopped, and consequently, available carbon source in the growth medium was assimilated and converted into lipid [49].

\subsection{Verification of model}

To test model validation and to evaluate the optimized medium versus the original medium, verification experiments were performed by cultivation both fungi under the above-mentioned optimal conditions and the control basal medium. Results showed that, under optimized conditions about $4.89 \mathrm{~g} / \mathrm{L}$ lipid obtained from 12 $\mathrm{g} / \mathrm{L}$ biomass, which represents lipid content of $40.75 \%$, compared with $10.8 \mathrm{~g} / \mathrm{L}$ biomass, $2.5 \mathrm{~g} / \mathrm{L}$ lipid yield and lipid content of $23.14 \%$. This revealed that optimization through RSM gave significant enhancement in lipid production by 1.7 fold increase. On the other hand, this result ( $40.75 \%)$ was in close agreement with the model-predicted response of $(41.4 \%)$, therefore the validation experiments confirmed the predicted values and the accuracy of the model.

\subsection{Lipid production using Orange peel as a carbon source}

Orange peel is highly economical substrate for oil production by Drechslera sp. with lipid yield of $3.65 \mathrm{~g} / \mathrm{L}$; this attributed to the high value (50) of $\mathrm{C} / \mathrm{N}$ ratio of orange peel, which is suitable for lipid production [72]. Moreover, the composition of orange peel made it a suitable substrate for fungal growth as it contains protein, soluble sugar, starch, lignin, cellulose, hemicellulose, fat, pectin, vitamin $C$ and organic acids (citric acid, oxalic acid, malonic acid, malic acid) [73]. A report by [74] illustrated that cultivation of the fungi Cunninghamella echinulata on orange peel resulted in lipid yield of $15-20 \mathrm{mg}$ of oil per gram of dry mass. 


\subsection{Fatty acid composition}

It is well known that, cultivation conditions and nutritional factors greatly effect on the fatty acid composition of SCOs [75]. In the present study, the effect of two carbon sources (sucrose and orange peel) on fatty acid composition of Drechslera sp. was tested. Gas chromatography analysis showed that the fatty acid profile of lipids produced from both cultures were found to contain a saturated, mono and poly unsaturated fatty acids with palmitic acid (SFA) as the most dominant one in both cultures. However, notable difference was observed with palmitic acid concentration in both cultures as it was 35\% with sucrose and $27.6 \%$ with orange peel (Table 12).

Significant difference of fatty acid composition between sucrose and orange peel was found with PUFA especially omega- 6 as it was noticed that omega- 6 PUFA concentration increased from $16.49 \%$ with sucrose culture to $30.93 \%$ with orange peel cultures and this increment was denoted to increase in concentration of both linolenic acid and gama-linolenic from 12.5 to $25 \%$ and 1.5 to $4.6 \%$, respectively. Thus, the fungal culture with orange peel as carbon source was recommended for gama-linolenic acid and linolenic acid production. On the other hand, culture with sucrose was recommended for Arachidonic acid production as it was absent from profile when orange peel was utilized.

It was found that oleic acid, elaidic acid and stearic acid (MUFAs) was slightly higher with orange peel than with sucrose. Overall, the total unsaturated fatty acids (PUFA \& MUFA) content was higher in the fungal oil obtained from orange peel culture $(58.68 \%)$ than with the oil obtained from sucrose $(41.99 \%)$. Other than previously mentioned fatty acids, bioactive FAs belonging to the $n-3, n-6$, and $n-9$ families were identified in both lipid profile, such as EPA, DHA, DGLA, Eicosenoic, Erucic acid and nervonic acid. These fatty acids concentrations were not high but their valuable value cannot be neglected.

In conclusion Drechslera sp. was considered a promising candidate for UFA production especially PUFA as the fungus give 33.31 with orange peel and 18.90 with sucrose.

Table (12): Fatty acid composition and concentrations of extracted total lipids from Drechslera sp. using sucrose and orange peel as a carbon source by GC/MS

\begin{tabular}{|c|c|c|c|}
\hline \multirow[t]{2}{*}{ Fatty acids } & & \multicolumn{2}{|c|}{ Percentage of each fatty acid } \\
\hline & & Sucrose & Orange peel \\
\hline Caproic acid & (C6) & 8.27 & 0.15 \\
\hline Caprylic acid & (C8) & 1.51 & 0.95 \\
\hline Capric acid & (C10) & 0.73 & 0.16 \\
\hline Undecanoic acid & (C11) & 0.16 & 0.09 \\
\hline Lauric acid & (C12) & 2.34 & 0.42 \\
\hline Tridecanoic acid & (C13) & 0.16 & 0.12 \\
\hline Myristoleic acid & (C14) & 0.35 & 0.24 \\
\hline Myristic acid & (C14) & 1.25 & 0.70 \\
\hline Cis-10-Pentadecenoic acid & (C15) & 0.53 & 0.28 \\
\hline Pentadecenoic acid & (C15) & 0.22 & 0.48 \\
\hline Palmitoleic acid & (C16) & 4.00 & 3.17 \\
\hline Palmitic & (C16) & 35.06 & 27.69 \\
\hline Cis-10-Heptadecenoic & (C17) & 0.63 & 0.34 \\
\hline Heptadecenoic & (C17) & 0.36 & 0.55 \\
\hline Gama-linolenic & (C18) & 1.56 & 4.68 \\
\hline Linolenic & (C18) & 12.52 & 25.10 \\
\hline Oleic & (C18) & 15.61 & 16.95 \\
\hline Elaidic & (C18) & 0.62 & 3.46 \\
\hline
\end{tabular}




\begin{tabular}{|c|c|c|c|}
\hline Stearic & (C18) & 3.89 & 4.86 \\
\hline Arachidonic & (C20) & 0.82 & 0 \\
\hline Cis-5,8,11,14,17-Eicosapentaenoic & (C20) & 0.85 & 1.25 \\
\hline Cis-8,11,14-Eicosatrienoic & (C20) & 0.82 & 0.60 \\
\hline Cis-11,14-Eicosadienoic & (C20) & 0.76 & 0.55 \\
\hline Cis-11-Eicosenoic & (C20) & 0.54 & 0.50 \\
\hline Cis-11,14,17-Eicosatrienoic & (C20) & 0.76 & 0.55 \\
\hline Arachidic & (C20) & 0.41 & 0.39 \\
\hline Heneicosanoic & (C21) & 0.54 & 0.46 \\
\hline Cis-4,7,10,13,16,19-Docosahexaenoic & ( C22) & 0.80 & 0.58 \\
\hline Cis-13,16-Docosadienoic & (C22) & 0 & 0 \\
\hline Erucic & (C22) & 0 & 0 \\
\hline Behenoic & (C22) & 1.00 & 1.28 \\
\hline Tricosanoic & (C23) & 0.65 & 0.97 \\
\hline Nervonic & (C24) & 0.83 & 0.62 \\
\hline Lignoceric & (C24) & 1.45 & 1.87 \\
\hline
\end{tabular}

\section{Conclusion}

The present research explores the capacity of an oleaginous fungus, Drechslera sp. to accumulate lipids with essential unsaturated fatty acids when cultivated on Czapek- Dox's medium. An increment of 1.7 fold in lipid content of optimized medium was achieved compared to original medium. Also, the feasibility of using an inexpensive and renewable waste substrate (orange peel) as a carbon source for lipid production by Drechslera sp. was also demonstrated. Thus, the study provides evidence that Drechslera sp. is considered as a promising fungus for economic production of SCO.

\section{Data Availability}

Email corresponding author for supplementary data

\section{Conflicts of Interest}

The authors declare no conflict of interest in this work

\section{Funding Statement}

This work supported completely by Genetic Engineering and Biotechnology Institute, City of Scientific Research and Technological Applications, Burgelarab, Alexandria, Egypt.

\section{Acknowledgments}

The authors gratefully acknowledge Dr. Marwa M. Eltarahony (Environmental Biotechnology Department, Genetic Engineering and Biotechnology Research Institute, City of Scientific Research and Technological Applications) for her efforts in declaring, analyzing the statistical experimental designs(PBD and RSM) and interpretation of the data. 


\section{Reference}

[1] Abedi E. and Sahari M. A. 2014. Long-chain polyunsaturated fatty acid sources and evaluation of their nutritional and functional properties. Food Science and Nutrition, vol. 2, no.5, pp. 443-463.

[2] Béligon V., Christophe G., Fontanille P., and Larroche C. 2016. Microbial lipids as potential source to food supplements. Current Opinion in Food Science. Elsevier Ltd, 7(October), pp. 35-42.

[3] Abu-Elreesh G. and Abd-El-Haleem D. 2014. Promising oleaginous filamentous fungi as biodiesel feed stocks: Screening and identification. European Journal of Experimental Biology, vol. 4(1), pp. 576-582.

[4] Patel A., Arora N., Mehtani J., Pruthi V. and Pruthi P. A. 2017a. Assessment of fuel properties on the basis of fatty acid profiles of oleaginous yeast for potential biodiesel production. Renew Sustain Energy, Rev 77, pp. 604-616.

[5] Liu M., Zhang X. and Tan T. 2016. The effect of amino acids on lipid production and nutrient removal by Rhodotorula glutinis cultivation in starch wastewater. Bioresource Technology, vol. 218, pp. 712-717.

[6] Sun Y., Liu J., Xie T., Xiong X., Liu W., Liang B. and Zhang Y. 2014. Enhanced lipid accumulation by chlorella vulgarisin a two-stage fed-batch culture with glycerol. Energy Fuels, vol.28, no.5, pp. 3172-3177.

[7] Madani M., Enshaeieh M., and Abdoli A. 2017. Single Cell Oil and its application for biodiesel production. Process Safety and Environmental protection, vol. 111, pp. 747-756.

[8] Papanikolaou S. and Aggelis G. 2011a. Lipids of oleaginous yeasts. Part I: Biochemistry of single cell oil production. European Journal of Lipid Science and Technology, vol. 113, pp.1031-1051.

[9] Papanikolaou S. and Aggelis G. 2011b. Lipids of oleaginous yeasts. Part II: technology and potential applications. European Journal of Lipid Science and Technology, vol. 113, pp. 1052-1073.

[10] Wei Y. Siewers V. and Nielsen J. (2017). Cocoa butter-like lipid production ability of non-oleaginous and oleaginous yeasts under nitrogen-limited culture conditions. Applied Microbiology and Biotechnology, vol. 101, pp. 3577-3585.

[11] Xu J., Du W., Zhao X., Zhang G. and Liu D. 2013. Microbial oil production from various carbon sources and its use for biodiesel preparation. Biofuels, Bioproducts and Biorefining, vol. 7, pp. 65-77.

[12] Subhash G. V., and Mohan S. V. 2014a. Lipid Accumulation for Biodiesel Production by Oleaginous Fungus Aspergillus Awamori: Influence of Critical Factors. Fuel, vol. 116, pp. 509-15.

[13] Fontani G., Corradeschi F., Felici A., Alfatti F., Migliorini S. and Lodi L. 2005.Cognitive and physiological effects of $\gamma-3$ polyunsaturated fatty acid supplementation in healthy subjects. European Journal of Clinical Investigation, vol. 35, pp. 691-699.

[14] MacLean H. C., Newberry J. S., Mojica A. W., Khanna P., Issa M., Suttorp J. M., Lim W. Y., Traina B. S., Hilton L., Garlan R. and Morton C. S. 2006. Effects of omega-3 fatty acids on cancer risk: A systematic review. JAMA, vol. 295, pp. 403-415.

[15] Uauy R., Hoffman R. D., Peirano P., Birch G. D. and Birch E. E. 2001. Essential fatty acids in visual and brain development. Lipids, vol. 36, pp. 885-895.

[16] Kikukawa H., Sakuradani E., Ando A., Shimizu S., and Ogawa J. 2018. Arachidonic acid production by the oleaginous fungus Mortierella alpina 1S-4: A review. Journal of Advanced Research,pp 0-7. 
[17] Fernandes B. S., Paulo J., Vieira F., Jares F., Mantelatto P. E., Zaiat M., Jares F. 2017. Critical Reviews in Biotechnology High value added lipids produced by microorganisms: a potential use of sugarcane vinasse. Critical Reviews in Biotechnology.

[18] Liang M. H. and Jiang J. G. 2013. Advancing oleaginous microorganisms to produce lipid via metabolic engineering technology. Prog Lipid via metabolic engineering technology. Progress in Lipid Research, vol. 52, pp. 395-408.

[19] Pinzi S., Leiva-Candia D., Lopez-Garcia I., Redel-Macias M. D. and Dorado M.P. 2014. Latest trends in feedstocks for biodiesel production. Biofuels, Bioproducts and Biorefining, vol. 8, pp. 126-143.

[20] Ageitos J. M., Vallejo, J. A., Veiga-Crespo,P and Villa T. G. 2011. Oily yeasts as oleaginous cell factories. Applied Microbiology and Biotechnology, vol. 90, pp.1219-1227.

[21] Baskar G., and Renganthan S. (2011). Screening of supplementary nitrogen source for fungal Lasparaginase production from soya bean meal flour using Latin square design. International Research Journal of Biochemistry and Biotechnology, vol. 1, pp. 1-7.

[22] Bajaj I. B., Lele S. S. and Singhal R. S. 2009. A statistical approach to optimization of fermentative production of poly (gamma-glutamic acid) from Bacillus licheniformis NCIM 2324. Bioresource Technology, vol. 100, pp. 826-832.

[23] Arul J. P., Sivakala K. K. and Jebakumar S. R. D. 2013. Formulation and Statistical Optimization of Culture Medium for Improved Production of Antimicrobial Compound by Streptomyces sp. JAJ06. International Journal of Microbiology, vol. 2013, pp. 9.

[24] Xu J., Zhao X., Wang W., Du W., Liu D. 2012. Microbial conversion of biodiesel by product glycerol to triacylglycerols by oleaginous yeast Rhodosporidium toruloides and the individual effect of some impurities on lipid production. Biochemical Engineering Journal, vol. 65, pp., 30-36.

[25] Kraisintu P., Yongmanitchai W. and Limtong S. 2010. Selection and optimization for lipid production of newly isolated oleaginous yeast, Rhodosporidium toruloides DMKU3-TK16. Kasetsart Journal (Nat Sci), vol. 44, pp. 436-445.

[26] Kimura K., Yamaoka M., and Kamisaka Y. 2004. Rapid estimation of lipids in oleaginous fungi and yeasts using Nile red fluorescence. Journal of Microbiological Methods, vol. 56, pp. 331-338.

[27] Devi P., SouzaL D., Kamat T., Rodrigues C. and Naik C. G. 2009. Batch culture fermentation of Penicillium chrysogenum and a report on the isolation, purification, identification and antibiotic activity of citrinin. Indian Journal of Marine Sciences, vol. 38, pp. 38-44.

[28] Helal G. A., Sarhan M. M., Abu S. A. N. K. and Abou E. E. K. 2006. Effect of Cymbopogon citratus essential oil on the growth, lipid content and morphogenesis of A. niger ML2-strain. Journal of Basic Microbiology, vol. 46, no. 6, pp. 456-469.

[29] Mishra S. K., Suh W. I., Farooq W., Moon M., Shrivastav A., Park M. S. and Yang J. W. (2014). Rapid quantification of microalgal lipids in aqueous medium by a simple colorimetric method. Bioresource Technology,vol. 155, pp. 330-333.

[30] Jiru T. M., Groenewald M., Pohl C., Stetn L., Kiggundu N. and Abate D. 2017. Optimization of cultivation conditions for biotechnological production of lipid by Rhodotorula Kratochvilovae (syn, Rhodosporidium kratochvilovae) SY89 for biodiesel preparation.3 Biotech, vol. 7, no, 2, pp. 1-11. 
[31] Muniraj I. K. 2012. Microbial Lipid Production and Nutrient Removal from Potato Processing Wastewater Using Oleaginous Fungi, phd, Thesis, Civil Engineering, College of Engineering and Informatics, National University of Ireland, Galway.

[32] Luttrell E. S. 1977. Correlations between conidial and ascigerous state characters in Pyrenophora, Cochliobolus and Setosphaeria. Review in Mycology, vol. 41, pp. 271-279.

[33] Elrashdy R., and Abd-El-Haleem D. 2005. Molecular analysis of cross-bacterial contamination detected during diagnosis HCV infection. Journal of Applied Sciences and Environmental Management, vol.9, pp. 510.

[34] Suh, S. O. and Nakase, T. 1995. Phylogenetic analysis of the ballistosporous anamorphic genera Udeniomyces and Bullera, and related basidiomycetous yeasts based on 18S rDNA sequences. Microbiology, vol. 141, pp. 901-906.

[35] Bligh E. G. and Dyer W. J. 1959. A rapid method of total lipid extraction and purification. Canadian Journal of Biochemistry and Physiology, vol. 37, pp. 911-917.

[36] Kosa M. and Ragauskas A. J. 2011. Lipids from heterotrophic microbes: Advances in metabolism research. Trends in biotechnol, vol. 29, no.2, pp. 53-61.

[37] Yang S., Wang W., Wei H., Van Wychen S., Pienkos P.T., Zhang M. and Himmel M. E. (2016). Comparison of nitrogen depletion and repletion on lipid production in yeast and fungal species. Energies, vol. 9: pp. 1-12.

[38] Kirrolia A., Bishnoi N. R. and Sing R. 2012. Effect of shaking, incubation temperature, salinity and media composition on growth traits of green microalgae Chlorococcum sp. Journal of Algal Biomass Utilization, vol. 3, no. 3, pp. 46-53.

[39] Ali T. H., El-Gamal M. S., El-Ghonemy D. H., Awad G. E. and Tantawy A. E. 2017. Improvement of Lipid Production from an Oil-Producing Filamentous Fungus, Penicillium Brevicompactum NRC 829, through Central Composite Statistical Design. Annals of Microbiology, vol. 67, no, 9, pp. 601-613.

[40] Somashekar D., Venkateshwaren G., Sambaiah K. and Lokesh B. R. 2003. Effect of culture conditions on lipid and gamma linolenic acid production by mucoraceous fungi. Process Biochemistry, vol, 38, pp. 17191724.

[41] Sha Q. 2013. A comparative study on four oleaginous yeasts on their lipid accumulating capacity. Swedish University of Agricultural Sciences, Department of Microbiology, Master's thesis, pp. 1-29.

[42] Li N., Deng Z. N., Qin Y. L., Chen C. L., and Liang Z. Q. 2007. Production of polyunsaturated fatty acids by Mucor recurvus sp. with sugarcane molasses as the carbon source. Food Technology and Biotechnology, vol. 46, no. 1, pp. 73-79.

[43] Ali T. H. and El-ghonemy D. H. 2014. Optimization of Culture Conditions for the Highest Lipid Production from Some Oleaginous Fungi for Biodiesel Preparation. Asian Journal of Applied Sciences, vol. 2, no. 5, pp. 600-609.

[44] Magdum S., S., Minde p. g., Adhyapak S. U. and Kalyanraman V. A. 2015. Competence evaluation of mycodiesel production by oleaginous fungal strains: Mucor circinelloides and Gliocladium roseum. International Journal of Energy and Environment (IJEE), Vol. 6, no. 4, pp. 377-382. 
[45] Saran S., Arushi M., Jyotsana D., and Saxena R. K. 2017. Process Optimization for Cultivation and Oil Accumulation in an Oleaginous Yeast Rhodosporidium Toruloides A29. Fuel, vol. 188, pp. 324-313.

[46] Dasgupta D., Suman S. K., Pandey D., Ghosh D., Khan R., Agrawal D., Jain R. K., Vadde V. T. and Adhikari D. K. (2013). Design and optimization of ethanol production from bagasse pith hydrolysate by a thermotolerant yeast Kluyveromyces sp. IIPE453 using response surface methodology. Springer Plus, vol. 2, pp.159-168.

[47] Gao D., Zeng J., Zheng Y., Yu X. and Chen S. 2013. Microbial lipid production from xylose by Mortierella isabellina. Bioresource Technology, vol. 133, pp. 315-321.

[48] Fang H., Zhao C., and Chen S. 2016. Single cell oil production by Mortierella isabellina from steam exploded corn stover degraded by three-stage enzymatic hydrolysis in the context of on-site enzyme production. Bioresource Technology, vol. 216, pp. 988-995.

[49] Ratledge C. 2002. Regulation of lipid accumulation in oleaginous micro-organisms. Biochemical Society Transactions, vol. 30, pp. 1047-1050.

[50] Sattur A. P. and Karanth N. G. 1989. Production of microbial lipids: II. Influence of C/N ratio-model prediction. Biotechnology and Bioengineering, vol. 34, pp. 868-871.

[51] Shen Q., Lin H., Wang Q., Fan X., Yang Y. and Zhao Y. 2015. Sweet potato vines hydrolysate promotes single cell oils production of Trichosporon fermentans in high-density molasses fermentation. Bioresource Technology, vol. 176, pp. 249-256.

[52] Liu J. Z., Weng L. P., Zhang Q. L., Xu H. and Ji L. N. 2003. Optimization of glucose oxidase production by Aspergillus niger in a bench top bioreactor using response surface methodology. World Journal of Microbiology and Biotechnology, vol. 19, pp. 317-323.

[53] Saban M. T., Dursun O. and Murat E. 2005. Optimization of amylase production by Bacillus sp. using response surface methodology. Process Biochemistry - Journal, vol. 40, pp. 2291.

[54] Manimekalai R. and Swaminathan T. 1999. Optimization of lignin peroxidase production from Phanerochaete chrysosporium using response surface methodology. Bioprocess Engineering, vol. 21, pp. 465-468.

[55] Prakash G., and Srivastava A. K. 2005. Statistical media optimization for cell growth and azadirachtin production in Azadirachta indica (A. Juss) suspension cultures. Process Biochemistry, vol. 40, pp. 37953800.

[56] Jiang P., Zhang Y., Shan Z. X., Zheng Q. H. 2013. Optimizing the extraction yield of polyprenols from needles of Cunninghamia Ianceolata (Lamb.) hook using response surface methodology and its antioxidative activities. BioResources, vol. 1, pp. 545-556.

[57] Zainal S., Nadzirah K., Noriham A., and Normah I., 2013. Optimization of beef tenderization treated with bromelain using response surface methodology (RSM). Agricultural science, vol. 4, no. 5B, pp. 65-72.

[58] Wang Y. X. and Lu Z. X. 2005. Optimization of processing parameters for the mycelial growth and extracellular polysaccharide production by Boletus spp. ACCC 50328. Process Biochemistry, vol. 40, pp. 1043-1051. 
[59] Vasconcelos A. F. D., Barbosa A. M., Dekker R. F. H., Scarminio I. S. and Rezende M. I. 2000. Optimization of laccase production by Botryosphaeria sp. in the presence of veratryl alcohol by the response-surface method. Process Biochemistry, vol. 35, pp. 1131-1138.

[60] Munk V., Paskova J. and Hanus J. 1993. Glucose oxidase of Aspergillus niger. Folia Microbiologica, vol. 8, pp. 203-214.

[61] El-Naggar N. and Abdelwahed N. 2014. Application of statistical Experimental Design for Optimization of Silver Nanoparticles Biosynthesis by a Nanofactory Strepomyces Virido chromogenes. Journal of Microbilogy, vol. 52, no. 1, pp. 53-63.

[62] Akhnazarova S. and Kafarov V. 1984. Experiment optimization in chemistry and chemical engineering. Mir Publishers. Moscow. Journal of Polymer Science: Polymer Letters Edition banner, vol. 22, no. 6, pp. 372-372

[63] El-Hadi A., El-Refai H., Shafei M., Zaki R. and Mostafa H. 2017. Statistical optimization of Lasparaginase production by using Fusarium solani. Egyptian Pharmaceutical Journal, vol. 16, no, 1, pp. 1623.

[64] Beopoulos A., Mrozova Z., Thevenieau F., Le Dall M. T., Hapala I., Apanikolaou S., Chardot T. and Nicaud J. M. 2008. Control of lipid accumulation in the yeast Yarrowia lipolytica. Applied and Environmental Microbiology, vol. 74, pp. 7779-7789.

[65] Zhu L.Y., Zong M. H. and Wu H. 2008. Efficient lipid production with Trichosporon fermentans and its use for biodiesel preparation. Bioresource Technology, vol. 99, pp. 7881-7885.

[66] Zhao X., Kong X. L., Hua Y. Y., Feng B. and Zhao Z. B. 2008. Medium optimization for lipid production through co-fermentation of glucose and xylose by the oleaginous yeast Lipomyces starkeyi. European Journal of Lipid Science and Technology, vol. 110, pp. 405-412.

[67] Jernejc K. and Legisa M. 2002. The influence of metal ions on malic enzyme activity and lipid synthesis in Aspergillus niger. FEMS Microbiology Letters, vol. 217, pp. 185-190.

[68] Guchhait R. H., Polakis S. E., Dimroth P., Stoll E. Moss J. and Lane M. D. 1974. Acetyl-CoA carboxylase system of E. coli: Purification and properties of the biotin protein carboxylase, carboxytransferase and carboxyl carrier protein components. Journal of Biological Chemistry, vol. 249, pp. 6633-6645.

[69] Amanullah A., McFarlane C. M., Emery A. N. and Nienow A. W. 2001. Scaledown model to simulate spatial pH variations in large-scale bioreactors. Biotechnology and Bioengineering, vol. 73, pp. 390-399.

[70] Yuan Z. and Hammes G. G. 1984. Elementary steps in the reaction mechanism of fatty acid synthase, $\mathrm{pH}$ dependence of NADPH binding and isotope rate effect for beta ketoacyl reductase. Journal of Biological Chemistry, vol. 11, pp. 6748-6751.

[71] Jang H. D., Lin Y. Y. and Yang S. S. 2005. Effect of culture media and conditions on polyunsaturated fatty acids production by Mortierella alpina. Bioresource Technology, vol. 96, no. 15, pp. 1633-1644.

[72] Chen H. C. and Chang C. C. 1996. Production of g-linolenic acid by the fungus Cunninghamella echinulata CCRC 31840. Biotechnology Progress, vol. 12, pp. 338-341.

[73] Rivas B., Torrado A., Torre P., Converti A. and Domnguez J. M. 2008. Submerged citric acid fermentation on Orange peel autohydrolysate. Journal of Agricultural and Food Chemistry, vol. 56, no. 7, pp. 2380-2387. 
[74] Gema H., Kavadia A., Dimou D., Tsagou V., Komaitis M. and Aggelis G. 2002. Production of $\gamma$-linolenic acid by Cunninghamella echinulata cultivated on glucose and orange peel. Applied Microbiology and Biotechnology, vol. 58, pp. 303-307.

[75] Subramaniam R., Dufreche S., Zappi M. and Bajpai R. 2010. Microbial lipids from renewable resources: production and characterization. Journal of Industrial Microbiology \& Biotechnology, vol. 37, pp. 12711287. 